\title{
Changes in the strength and width of the Hadley Circulation since 1871
}

\author{
J. Liu ${ }^{1}$, M. Song ${ }^{1}$, Y. Hu${ }^{2}$, and X. Ren ${ }^{3}$ \\ ${ }^{1}$ State Key Laboratory of Numerical Modeling for Atmospheric Sciences and Geophysical Fluid Dynamics, \\ Institute of Atmospheric Physics, Chinese Academy of Sciences, Beijing, China \\ ${ }^{2}$ Department of Atmospheric and Oceanic Sciences, School of Physics, Peking University, Beijing, China \\ ${ }^{3}$ Institute of Atmospheric Physics, Chinese Academy of Sciences, Beijing, China
}

Correspondence to: J. Liu (jliu@lasg.iap.ac.cn)

Received: 29 December 2011 - Published in Clim. Past Discuss.: 9 March 2012

Revised: 4 June 2012 - Accepted: 13 June 2012 - Published: 19 July 2012

\begin{abstract}
Recent studies demonstrate that the Hadley Circulation has intensified and expanded for the past three decades, which has important implications for subtropical societies and may lead to profound changes in global climate. However, the robustness of this intensification and expansion that should be considered when interpreting long-term changes of the Hadley Circulation is still a matter of debate. It also remains largely unknown how the Hadley Circulation has evolved over longer periods. Here, we present long-term variability of the Hadley Circulation using the 20th Century Reanalysis. It shows a slight strengthening and widening of the Hadley Circulation since the late 1970s, which is not inconsistent with recent assessments. However, over centennial timescales (1871-2008), the Hadley Circulation shows a tendency towards a more intense and narrower state. More importantly, the width of the Hadley Circulation might have not yet completed a life-cycle since 1871 . The strength and width of the Hadley Circulation during the late 19th to early 20th century show strong natural variability, exceeding variability that coincides with global warming in recent decades. These findings raise the question of whether the recent change in the Hadley Circulation is primarily attributed to greenhouse warming or to a long-period oscillation of the Hadley Circulation - substantially longer than that observed in previous studies.
\end{abstract}

\section{Introduction}

The Hadley Circulation (ascent near the equator and subsidence in the subtropics) is a fundamental regulator of the Earth's energy budget, i.e. redistribution of energy from tropics to higher latitudes. The Hadley Circulation determines the precipitation pattern in the tropics and subtropics, i.e. the prevalence of rain in the moist inner tropical regions and the dry conditions in the subtropical regions (e.g. Diaz and Bradley, 2004).

In recent years, there has been a substantial interest in the decadal change of the Hadley Circulation, focusing on its two aspects: strength and width. Satellite observations provided evidence of an increase of thermal radiation emitted by Earth and a decrease of reflected solar radiation in the tropics from the mid-1980s to the 1990s (Chen et al., 2002; Wielicki et al., 2002). Further analysis suggested such change might be attributed to a decadal strengthening of the Hadley Circulation (Chen et al., 2002). Various widely used reanalyses show that the winter northern Hadley Circulation has strengthened over the past few decades (Diaz and Bradley, 2004; Mitas and Clement, 2005; Song and Zhang, 2007), although no discernible trend is found in the global radiosonde observations for 1959-1989 (Mitas and Clement, 2004). By contrast, the majority of coupled and atmospheric-only model simulations showed a decrease or no increase of the winter Hadley Circulation during the late 20th century (Mitas and Clement, 2006). The ensemble mean of the IPCC AR4 climate model simulations (SRES A1B emission scenario) further suggested that the Hadley Circulation would weaken 
by $9 \%$ by the late 21 st century (Tanaka et al., 2005). Because the signal is not consistent across the reanalyses, radiosonde observations, and model simulations, there are still questions about the robustness of the strengthening in recent decades that should be considered when interpreting longterm changes in the strength of the Hadley Circulation.

Satellite-borne Microwave Sounding Unit data showed an enhanced mid-latitude tropospheric warming for 1979-2005, which indicated a poleward shift of subtropical jet streams (Fu et al., 2006). Because the subtropical jet streams mark the poleward boundary of the Hadley Circulation, such change suggests a widening of the Hadley Circulation in recent decades. Various commonly used reanalyses and outgoing long-wave radiation (OLR) data showed a total Hadley Circulation widening of $\sim 2-4.5^{\circ}$ in latitude since 1979 (Hu and $\mathrm{Fu}, 2007)$. The total column ozone measured by the Total Ozone Mapping Spectrometer revealed that the relative area of the tropical ozone regime extended poleward in the Northern Hemisphere by $\sim 2.7^{\circ}$ in latitude for 1979-2003 (Hudson et al., 2003). Radiosonde measurements exhibit that the frequency of occurrence of high tropopause days in the subtropics has systematically increased, indicating a widening of the tropical belt of $\sim 5-8^{\circ}$ in latitude for 1979-2005 (Seidel and Randel, 2007). The IPCC AR4 climate model simulations also showed Hadley Circulation widening in response to increased greenhouse gases (Lu et al., 2007; Johanson and $\mathrm{Fu}, 2009)$. However, the widening appears to be nearly an order of magnitude smaller in the IPCC AR4 simulations than those in the observations (Johanson and $\mathrm{Fu}, 2009$ ). This suggests that further studies are necessary to confirm long-term changes in the meridional extent of the Hadley Circulation.

To date, it is unclear what observational and model biases cause the above discrepancies in the strength and width of the Hadley Circulation in response to climate change, e.g. reanalyses and models show fundamentally different thermodynamic structures in the tropical troposphere (Mitas and Clement, 2006), and radiosonde observations and their assimilation in reanalyses might be one of the problems (Santer et al., 2005; Shewood, 2007). The modern reanalyses now available extend from no earlier than 1948 to the present (e.g. the National Center for Environmental Prediction/National Center for Atmospheric Research reanalysis - NCEP/NCAR - starts from 1948; Kistler et al., 2001), leaving many important climate events uncovered. It remains largely unknown how the strength and width of the Hadley Circulation have evolved over longer periods, and how future climate change may affect the Hadley Circulation. Here, we analyze long-term variation of the Hadley Circulation using the 20th Century Reanalysis Version 2 (20CR2), which provides the first estimates of global tropospheric variability from 1871 to 2008 (Compo et al., 2011). Preliminary validations suggest that the 20CR2 depicts more realistic vertical structures of temperature trends in the tropics and subtropics, and probably suffers less from spurious trends than any previous reanalyses (see discussions of the key differences between the 20CR2 and previous reanalyses, and evaluations of the 20CR2 in Sect. 2).

\section{Data and method}

In this study, our results and conclusions are based on the 20th Century Reanalysis Version 2. Previous reanalyses assimilated the available observations using a 3D-Var data assimilation technique with the same weight given to the first guess throughout the reanalysis period. However, significant variations in data density (and accuracy) for the past half century have resulted in significant inhomogeneities from the suboptimal assimilation of observations from very different observational networks, causing problems including incorrect tropical variability, understated storm track variability, and spurious long-term trends. Sparse observations during the early 20th century and especially the 19th century further compromise the ability of 3D-Var systems to produce reliable reanalyses for these earlier periods (Bengtsson et al., 2004; Whitaker et al., 2004). Recent studies have demonstrated the feasibility of generating reliable reanalyses for these earlier periods using only surface observations, e.g. surface pressure has been measured consistently since the late 1800 s and standard corrections are known for earlier observations. Surface pressure, through geostrophy, provides a reasonable approximation to the barotropic part of the flow, which accounts for a substantial part of the total flow. The surface pressure tendency, which is related to the vertically integrated mass flux divergence, provides further information about the tropospheric circulation that can be captured by a data assimilation system and more advanced data assimilation methods (e.g. the Ensemble Kalman Filter or 4DVar). Motivated by these considerations, the 20CR2 utilizes an Ensemble Filter data assimilation system, a new version of the NCEP atmospheric-land model, newly compiled surface pressure observations, and the radiative effects of historical time-varying $\mathrm{CO}_{2}$ concentrations, volcanic aerosol and solar variations to generate a reanalysis spanning 1871 to 2008 (Compo et al., 2011).

The 20CR 2 only became available to the scientific community in 2010. Consequently, the evaluation of the 20CR2 is in its early stages, which imposes some uncertainty on our results. However, some evaluations have demonstrated that the 20CR2 successfully incorporates surface pressure observations and its beneficial impact on estimates of the global tropospheric circulation (Compo et al., 2011). 20CR2 is also generally in good agreement with two early shipbased upper-air datasets from 1906/1907 and 1938/1939 (Brönnimann et al., 2011). In order to further evaluate the performance of the 20CR2 in the tropics and subtropics and to reduce the uncertainties in our conclusions, we compared the 20CR2 and NCEP/NCAR with observations for 1958-2010. We used the annual-mean temperature anomalies in the tropics and subtropics $\left(30^{\circ} \mathrm{S}-30^{\circ} \mathrm{N}\right)$ from the 
radiosonde atmospheric temperature products for assessing climate (RATPAC, Free et al., 2005), which is less influenced by the temporal inhomogeneities due to historical changes in instruments and measurement practices. Linear trends and their uncertainties were calculated as a function of height. The same procedure was applied to the 20CR2 and NCEP/NCAR temperature anomaly fields. As shown in Fig. 1, the observations display a warming trend extending from surface to the upper troposphere, and the upper troposphere is warming faster than the surface. At all levels, temperature trends in the 20CR2 are considerably closer to the observations than that of the NCEP/NCAR. The improved accuracy in the 20CR 2 compared to the NCEP/NCAR is most pronounced in the lower and upper troposphere. There are quantitative differences between the trends in the 20CR2 and observations. However, the magnitudes of the trends in the 20CR2 and in the observations are not significantly different when their uncertainties are taken into account as compared to those of the NCEP/NCAR.

A conventional way to depict the Hadley Circulation is to calculate the mass stream function (MSF, Oort and Yienger, 1996), which is defined by $\Psi=\frac{2 \pi a \cos \varphi}{g} \int_{0}^{p} \bar{v} \mathrm{~d} p$, where $\Psi$ is MSF, $\bar{v}$ is the zonally-averaged north/south (meridional) velocity, $a$ is the Earth's radius, $g$ is gravity, $\varphi$ is latitude, and $p$ is pressure level. The MSF at a given latitude and pressure level is equal to the rate at which mass is being transported meridionally between that pressure level and the top of the atmosphere. Note that the Hadley Circulation is a zonal-mean quantity, which is also known as the mean meridional circulation.

\section{Result and discussion}

To describe temporal variation of the strength of the northern (southern) Hadley Circulation, we use the maximum (minimum) value of the zonal-mean mass stream function (as described in the methods summary) occurring within the latitudinal zone of $0-30^{\circ} \mathrm{N}\left(0-30^{\circ} \mathrm{S}\right)$. As shown in Fig. 2a, a substantial multi-decadal variability is evident in the strength of the northern Hadley Circulation, e.g. a pronounced strengthening from the 1870 s to the mid-1920s, followed by a weakening to the late 1960s, and then no discernible trend (or a slight strengthening) to the present. Overlaid on such multi-decadal variability, there is an upward trend $\left(0.61 \times 10^{10} \mathrm{~kg} \mathrm{~s}^{-1},>99 \%\right.$ significance $)$ indicating a strengthening of the northern Hadley Circulation since 1871. The strengthening of the northern Hadley Circulation is persistent for all the seasons, with the most pronounced trend in spring (Fig. 3a). The strength of the southern Hadley Circulation also shows an increasing trend $\left(0.91 \times 10^{10} \mathrm{~kg} \mathrm{~s}^{-1}\right.$, $>99 \%$ significance) since 1871 (Fig. 2b), although an anomalous decrease is found during the 1910s and 1920s.

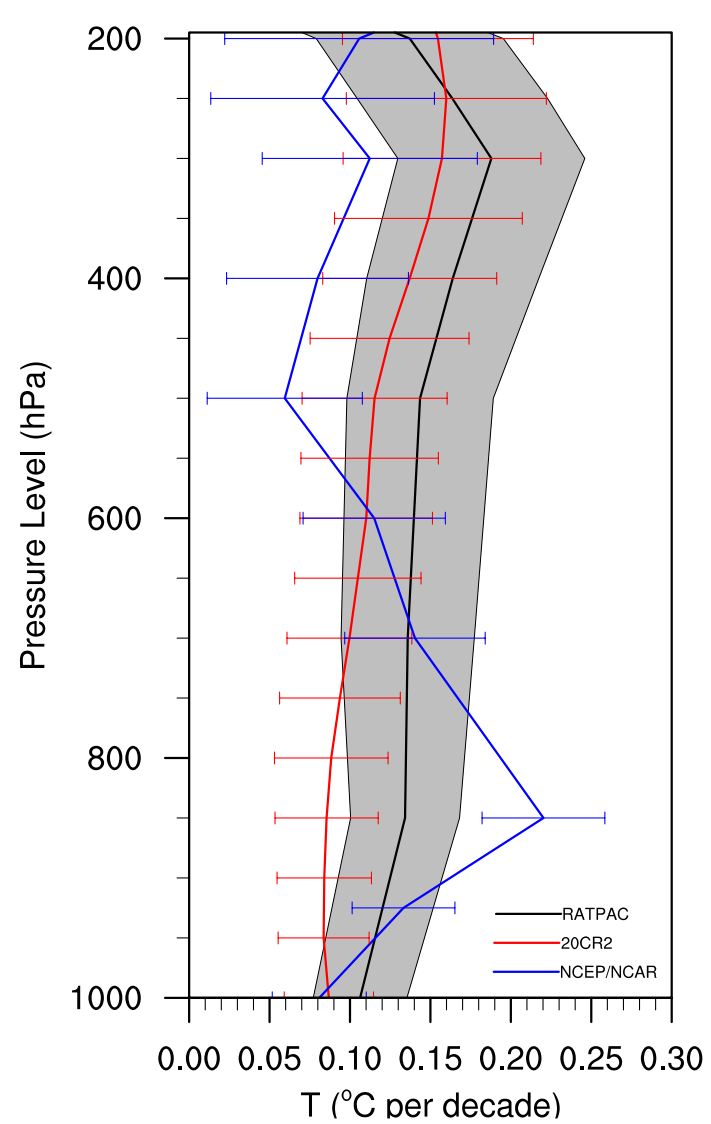

Fig. 1. Comparison of the vertical structures of the annual-mean temperature trends $\left({ }^{\circ} \mathrm{C}\right.$ per decade) in the 20CR2, NCEP/NCAR and observations (RATPAC) for 1958-2010. Also shown are the $95 \%$ confidence intervals (grey band for observations and error bars for the 20CR2 and NCEP/NCAR).

The strengthening of the southern Hadley Circulation occurs in all the seasons except summer (Fig. 3b).

The vertical and latitudinal structure of the trend in the strength of the Hadley Circulation shows that the intensification of the northern and southern Hadley Circulation extends from surface to the upper troposphere (Fig. 4b). The maximum intensification of the northern Hadley Circulation is more toward the lower level $(\sim 850-\mathrm{hPa})$ and equator $\left(\sim 4^{\circ} \mathrm{N}\right)$ as compared to that of the southern counterpart $\left(\sim 500-\mathrm{hPa}\right.$ and $\left.10^{\circ} \mathrm{S}\right)$. Compared with the climatological maximum values of the northern and southern Hadley Circulation (Fig. 4a), the strength of the northern and southern Hadley Circulation has increased by $\sim 26.9 \%$ and $12 \%$, respectively, since 1871.

As shown in Fig. 2c, the northern edge of the northern Hadley Circulation exhibits a remarkable equatorward shift from the 1870 s to the early 1920 s, followed by a gradually poleward shift to the present. Overall, the northern edge of the northern Hadley Circulation shows a slightly equatorward-moving tendency since $1871\left(0.44^{\circ}\right.$ in latitude, not statistically significant). The trends are strongly 

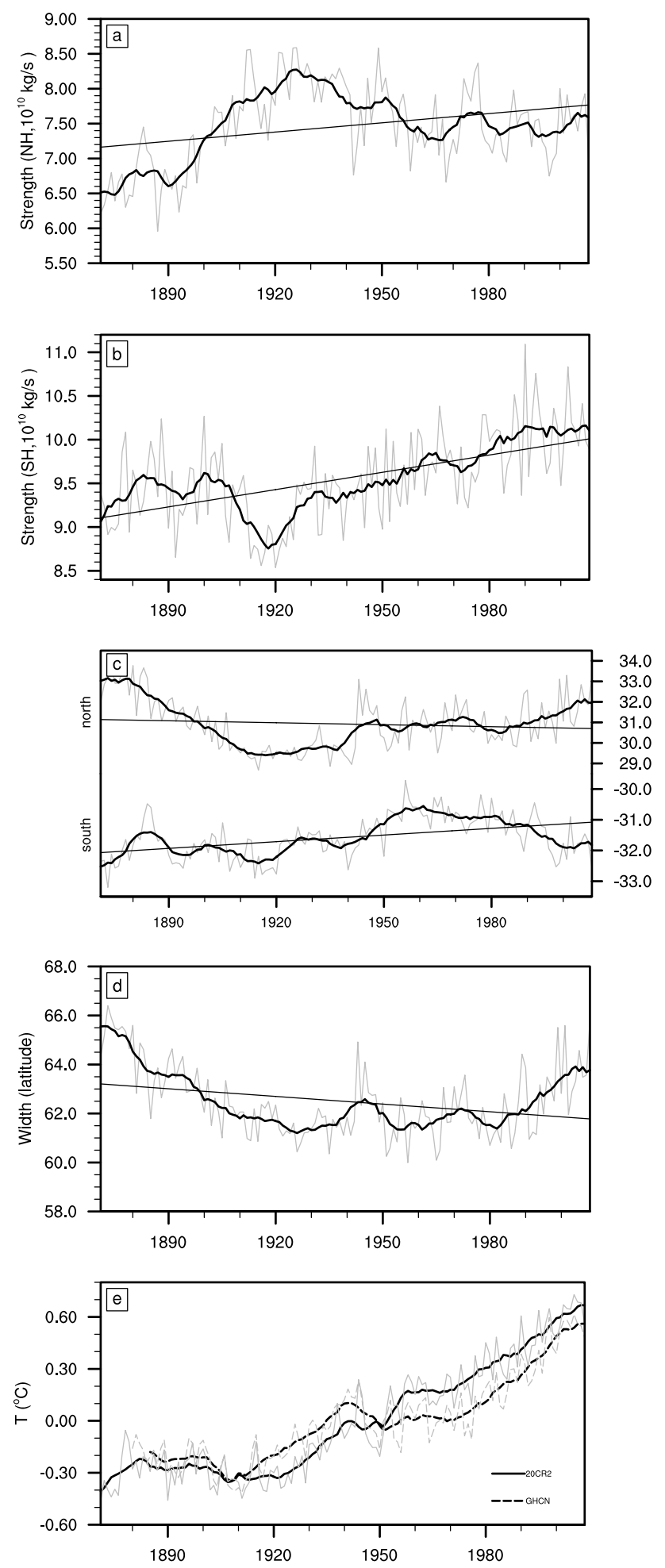

Fig. 2. Time series of the annual-mean (grey line) and 10-yr running mean (black line) strength, edge and width of the Hadley Circulation for 1871-2008: (a) the strength of northern component, (b) the strength of the southern component, (c) the poleward-edge of the northern and southern components, and (d) the width and (e) time series of the annual-mean GHCN surface temperature and 20CR2 surface air temperature for 1871-2008.
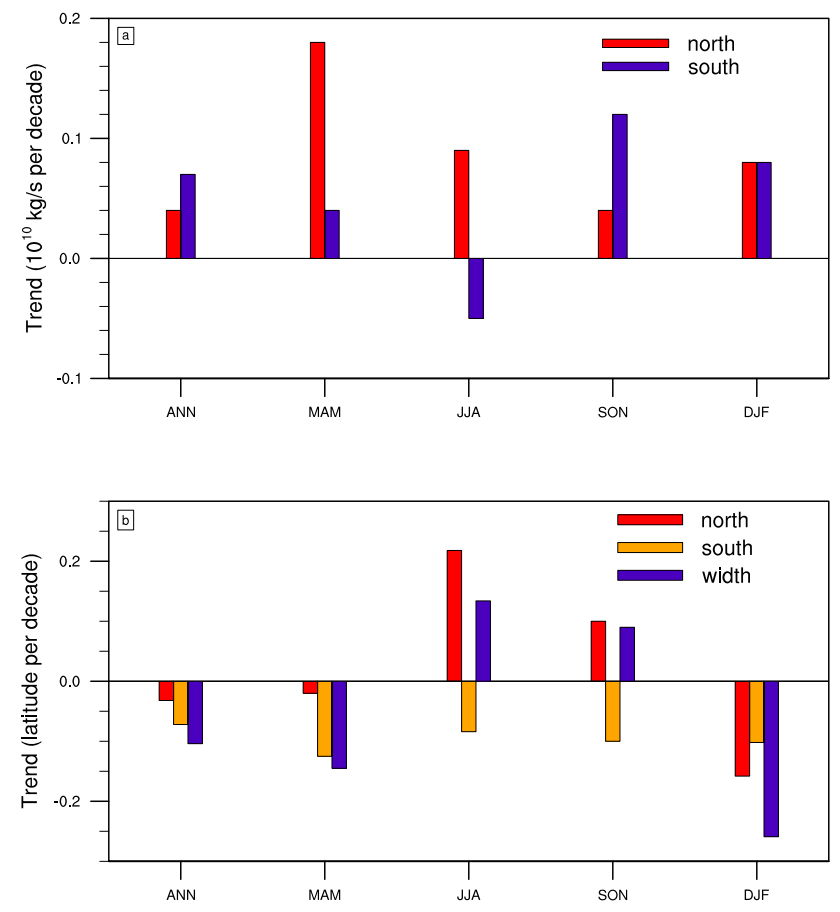

Fig. 3. Annual and seasonal trends of (a) the strength of the northern and southern Hadley Circulation $\left(\times 10^{10} \mathrm{~kg} \mathrm{~s}^{-1}\right.$ per decade), and (b) the poleward-edge and width of the Hadley Circulation (latitude per decade) for 1871-2008.

seasonally dependent - equatorward in winter and spring and poleward in summer and autumn (Fig. 3b). The southern edge of the southern Hadley Circulation shows a significant equatorward-moving tendency since $1871\left(1^{\circ}\right.$ in latitude, $>99 \%$ significance), although a poleward shift is found starting from the late 1970s (Fig. 2c). The equatorward shift of the southern edge of the southern Hadley Circulation occurs in all the seasons (Fig. 3b). We note that the northern and southern edges of the Hadley Circulation tend to diverge starting from the late 1970 s, which is consistent with the identified expansion of the Hadley Circulation in the aforementioned studies.

Figure $2 \mathrm{~d}$ shows the width of the Hadley Circulation, which is defined as the distance between the northern and southern edges of the Hadley Circulation. The Hadley Circulation shrunk by $\sim 4-5^{\circ}$ in latitude from the 1870 s to the mid-1920s, followed by two major expansion periods (from the mid-1920s to the mid-1940s and from the late 1970s to the present) which are in accordance with two major warming periods (1925-1944 and 1978-present) found in the observations (Jones et al., 1999; Hansen et al., 2010). We speculate the width of the Hadley Circulation might have not yet completed a cycle since 1871, although there is no guarantee that the behavior of the width of the Hadley Circulation has to be cyclical. To further confirm the identified secular variability, we performed a spectral analysis on the time series 

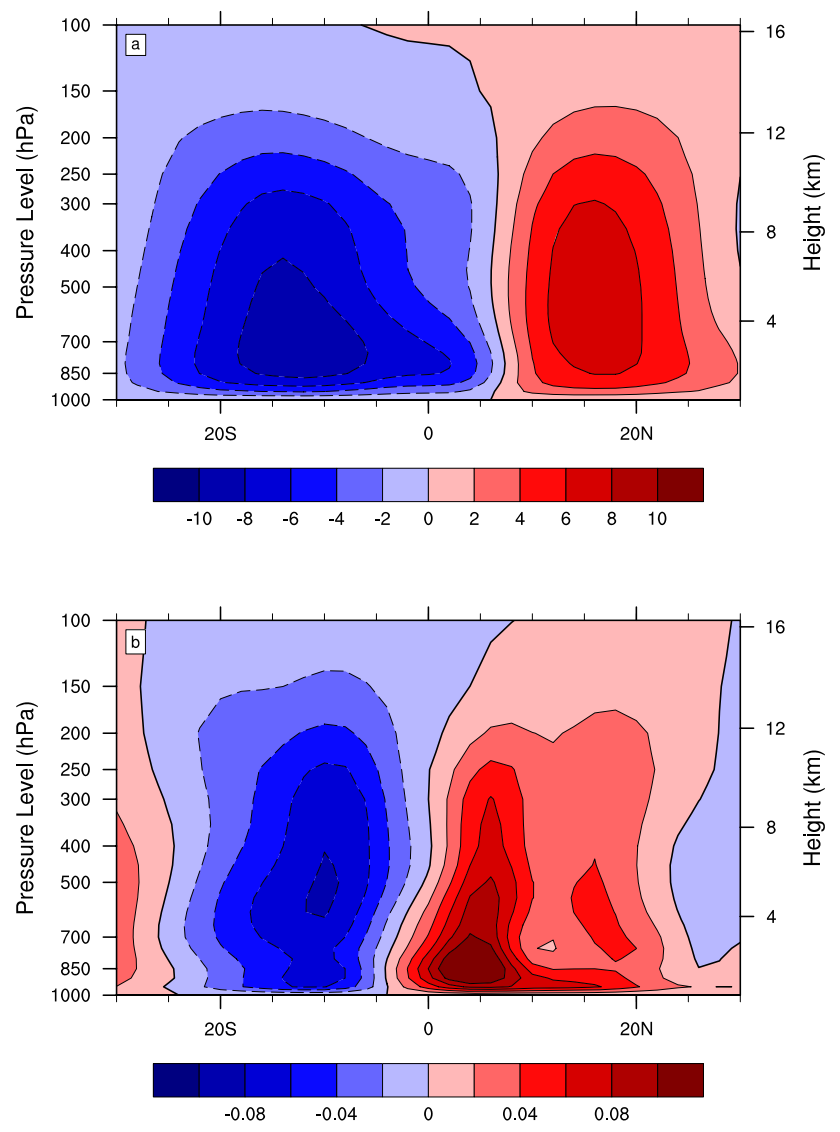

Fig. 4. (a) Climatology $\left(\times 10^{10} \mathrm{~kg} \mathrm{~s}^{-1}\right)$ and (b) trend $\left(\times 10^{10}\right.$ $\mathrm{kg} \mathrm{s}^{-1}$ per decade) of the mass stream function of the Hadley Circulation for 1871-2008.

of the width of the Hadley Circulation. The spectral analysis indicates that the width of the Hadley Circulation exhibits a clear secular peak indicative of centennial-scale variability that is distinct from the null hypothesis of a red-noise stochastic process, (> $99 \%$ significance, Fig. 5). Overall, the Hadley Circulation shows a tendency toward a narrower state during $1871-2008\left(-1.44^{\circ}\right.$ in latitude, $>99 \%$ significance $)$.

Despite a large number of observational and modeling studies, it remains unclear how the strength and width of the Hadley Circulation are related (Schneider et al., 2010). As shown in Table 1, significant out-of-phase relationships are found between the strength, and the width and northern edge of the Hadley Circulation, even with the trends removed. By contrast, no strength-width relationship exists for the southern counterpart, although significant correlation is found between the strength and the southern edge of the southern Hadley Circulation. This indicates that the northern Hadley Circulation might dominate the southern counterpart in modulating the meridional extent of the Hadley Circulation.

It is instructive to analyze the relationship between the covariability of the strength and width of the Hadley Circulation and surface temperature. The Global Historical
Table 1. Correlations between the strength, width and edge of the Hadley Circulation, and regressions of the strength and width of the Hadley Circulation on the averaged 20CR2 surface air temperature in the tropics and subtropics (TSSAT).

\begin{tabular}{|c|c|c|c|c|}
\hline & \multicolumn{3}{|c|}{ Correlation } & \multirow{2}{*}{$\begin{array}{r}\text { Regression } \\
\left(10^{10} \mathrm{~kg} \mathrm{~s}^{-1} \text { per }{ }^{\circ} \mathrm{C}\right. \\
\text { TSSAT }\end{array}$} \\
\hline & Width & Edge $(N)$ & Edge $(S)$ & \\
\hline Strength $(N)$ & -0.59 & -0.59 & -0.17 & $-0.66(-\mathbf{0 . 8 8})$ \\
\hline Strength $(S)$ & -0.06 & 0.19 & -0.46 & $1.67(1.28)$ \\
\hline Width & 1 & 0.88 & 0.48 & $-0.25(\mathbf{2 . 0 9})$ \\
\hline
\end{tabular}

Note: $>99 \%$ significance is in bold type.

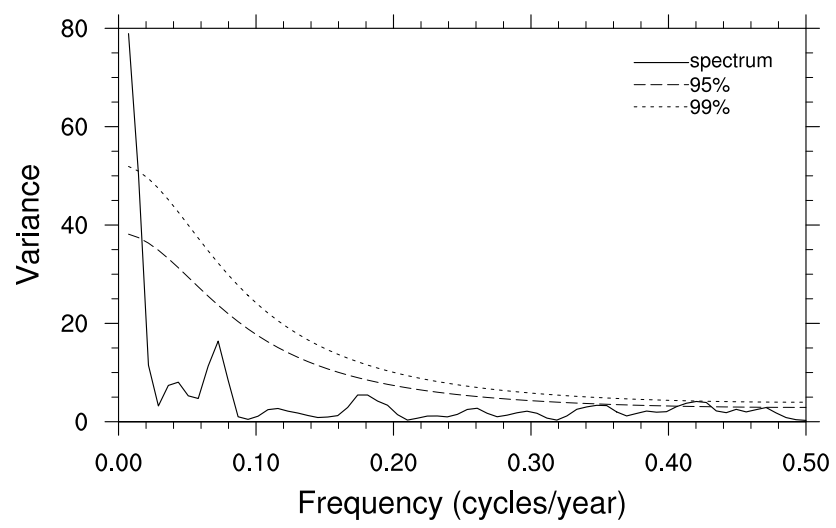

Fig. 5. Spectrum and red-noise confidence intervals for the time series of the annual mean width of the Hadley Circulation.

Climatology Network (GHCN) data (http://www1.ncdc. noaa.gov/pub/data/cmb/ghcnm/ghcnm-v3.pdf) shows that the global-mean surface temperature has warmed by $0.06^{\circ} \mathrm{C}$ for 1880-2008 (Fig. 2e). Compared to the observations, the global-mean near surface air temperature of the 20CR2 shows comparable warming trend $\left(0.06^{\circ} \mathrm{C}\right.$ for $\left.1880-2008\right)$, and coherent variation (the correlation between the 20CR2 and $\mathrm{GHCN}$ is $0.94,>99 \%$ significance).

It has been suggested that the Hadley Circulation would weaken in association with global warming (Diaz and Bradley, 2004; Lu et al., 2007; Vecchi and Soden, 2007), which is based on the relationship between the meridional surface temperature gradient and the strength of the Hadley Circulation (Diaz and Bradley, 2004). The IPCC AR4 model projected a decrease of convective overturning in the tropics as climate warms (Vecchi and Soden, 2007), but some studies demonstrate that the Hadley Circulation has strengthened in recent decades, particularly in winter. Here, our analysis shows the Hadley Circulation has strengthened in accordance with the increase of the global-mean surface temperature since 1871, but the northern Hadley Circulation shows substantial multi-decadal fluctuations.

It has also been suggested that the meridional extent of the Hadley Circulation would expand in association with greenhouse warming. This is based on the postulation that the 
extent of the Hadley Circulation is determined by the latitude of baroclinic instability. Under global warming conditions, the subtropical static stability increases due to an established consequence of moist thermodynamics which pushes the baroclinic instability zone poleward, and consequently causes the outer boundary of the Hadley Cell to extend poleward (Lu et al., 2007). Here, our analysis shows that the Hadley Circulation has shrunk by $1.44^{\circ}$ in latitude in accordance with surface warming during 1871-2008.

The sustained increase in the width of the Hadley Circulation for the past few decades that has occurred simultaneously with a significant positive trend in the global-mean surface temperature has led to the speculation that the changes in both fields are the result of greenhouse warming. Meanwhile, examination of the strength and width of the Hadley Circulation shows substantial changes during the late 19th to early 20th century, which features low atmospheric concentration of greenhouse gases. We further divide the entire period (1871-2008) into (1) a cold period (1871-1925), which features a slight decrease or no increase in the global-mean surface air temperature, and (2) a warm period (1926-2008), which is characterized by a quite persistent rise in the globalmean surface air temperature (Fig. 2e). As shown in Fig. 6, the strength of the northern Hadley Circulation decreases with the increasing surface air temperature, although such dependence during the cold period is not statistically significant (Table 1). The opposite is the case for the strength of the southern counterpart, which increases with the increasing surface air temperature. This suggests that the northern and southern components of the Hadley Circulation have opposite strength-temperature relationships. The width of the Hadley Circulation does show an expansion with the increasing surface air temperature during the warm period, but no dependence on surface temperature is found during the cold period. The width of the Hadley Circulation changes nonmonotonically with surface temperature, showing different sensitivity to cold and warm conditions.

\section{Conclusions}

We conclude that the 20CR2 does indicate a slight strengthening and widening of the Hadley Circulation for the past three decades, corroborated by the results of recent analyses. However, over longer periods (1871-2008), the Hadley Circulation has become stronger and narrower. Moreover, we speculate that the width of the Hadley Circulation might have not finished a full life-cycle since the 1870s, which indicates the observed expansion in recent decades might be a reflection of a long-period oscillation. The position of the Intertropical Convergence Zone (ITCZ) is effectively a tracer of the horizontal scale of the Hadley cell $(\mathrm{Hu}$ et al., 2007). Growing paleoclimatic proxy evidence indicates centennial-scale oscillatory behavior of the position of the ITCZ for the past several millennia, i.e. the planktic foraminifera Globigerinoides sacculifer in Gulf of Mexico
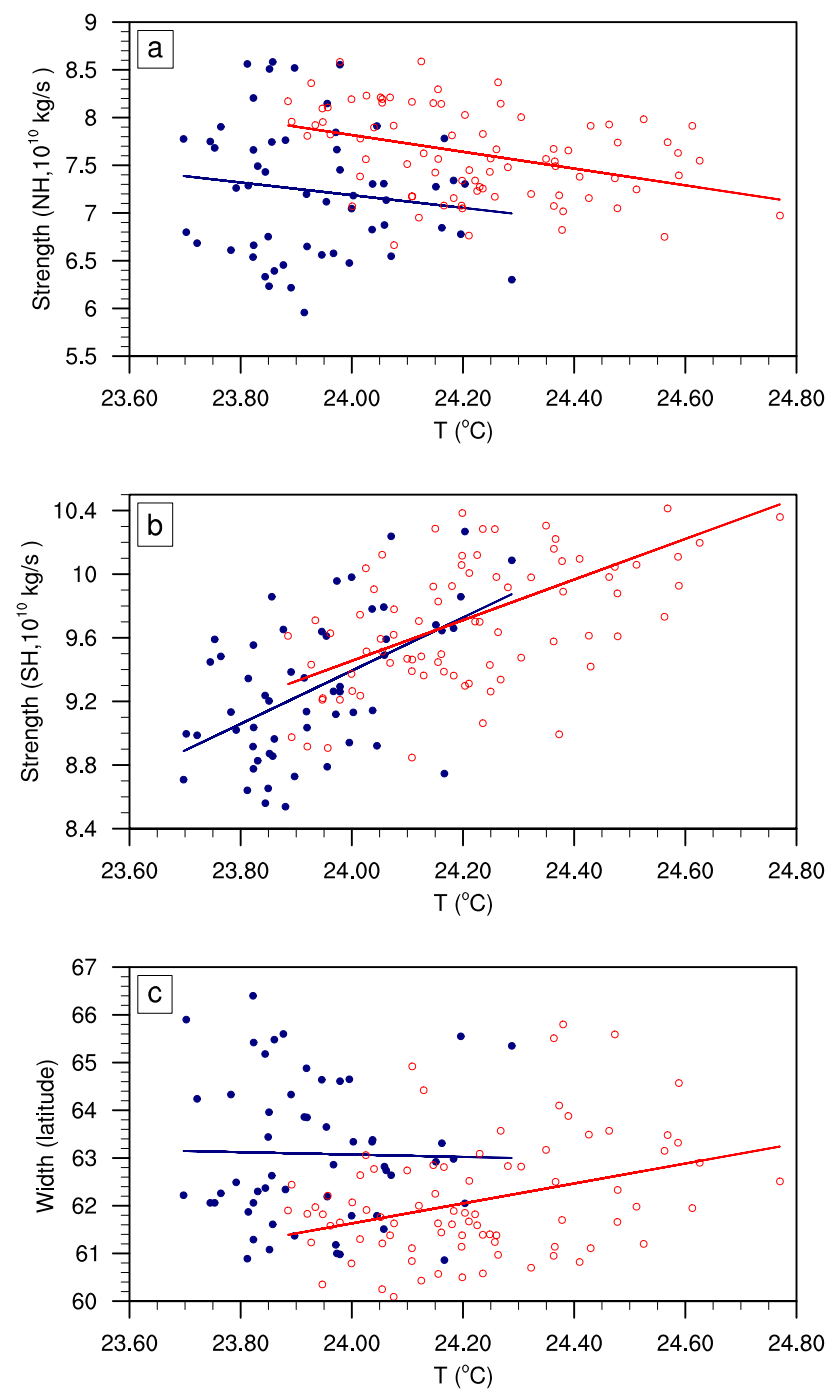

Fig. 6. Scatter plots of the strength and width of the Hadley Circulation versus the averaged 20CR2 surface air temperature in the tropics and subtropics $\left(30^{\circ} \mathrm{S}-30^{\circ} \mathrm{N}\right)$ during the cold $(1871-1925$, blue) and warm (1926-2008, red) periods: (a) the strength of the northern component, (b) the strength of the southern component, and (c) the width.

sediments show the distinct century-scale cyclicity of ITCZ (Poore et al., 2004). Although the identified secular variability of the width of the Hadley Circulation is not inconsistent with the paleoproxy evidence, the interpretation of such variability must be treated with caution because the science is not yet at a stage where sound judgments on this matter can be offered. The long-term changes of the Hadley Circulation might be resolved by a network of proxy observations that describe tropical-subtropical divergence gradients and variations.

The strength and width of the Hadley Circulation during the late 19th to early 20th century experienced substantial changes that exceed the changes associated with global warming in recent decades. A simple relationship between 
the strength and width of the Hadley Circulation and surface temperature is not supported. These findings are intriguing and raise the question of whether the recent changes in the Hadley Circulation are primarily due to greenhouse warming or long-term change of the Hadley Circulation (e.g. variability of the Hadley Circulation at centennial timescales). Attributions of those changes require a deeper understanding of how the strength and width of the Hadley Circulation is controlled under various dynamical regimes, even in the present climate state.

Acknowledgements. This research is supported by 973 program (2011CB309704) and NSFC (41176169).

Edited by: D. Wheeler

\section{References}

Bengtsson, L., Hodges, K., and Hagemann, S.: Sensitivity of the ERA-40 reanalysis to the observing system: Determination of the global atmospheric circulation from reduced observations, Tellus A, 56, 456-471, 2004.

Brönnimann, S., Compo, G. P., Spadin, R., Allan, R., and Adam, W.: Early ship-based upper-air data and comparison with the Twentieth Century Reanalysis, Clim. Past, 7, 265-276, doi:10.5194/cp7-265-2011, 2011.

Chen, J., Carlson, B., and Del Genio, A.: Evidence for strengthening of the tropical general circulation in the 1990s, Science, 295, 838-841, 2002.

Compo, G., Whitaker, J., Sardeshmukh, P., Matsui, N., Allan, R., Yin, X., Gleason, B., Vose, R., Rutledge, G., Bessemoulin, P., Bronnimann, S., Brunet, M., Crouthamel, R., Grant, A., Groisman, P., Jones, P., Kruk, M., Kruger, A., Marshall, G., Maugeri, M., Mok, H., Nordli, Ø., Ross, T., Trigo, R., Wang, X., Woodruff, S., and Worle, S.: The Twentieth Century Reanalysis Project, Q. J. Roy. Meteorol. Soc., 137, 1-28, 2011.

Diaz, H. and Bradley, R. (Eds.): The Hadley Circulation, Present, Past and Future, Kluwer Academic, Dordrecht, 511 pp., 2004.

Free, M., Seidel, D., Angell, J., Lanzante, J., Durre, I., and Peterson, T.: Radiosonde Atmospheric Temperature Products for Assessing Climate (RATPAC): A new dataset of largearea anomaly time series, J. Geophys. Res., 110, D22101, doi:10.1029/2005JD006169, 2005.

Fu, Q., Johanson, C., Wallace, J., and Reichler, T.: Enhanced midlatitude tropospheric warming in satellite measurements, Science, 312, 1179, doi:10.1126/science.1125566, 2006.

Hansen, J., Ruedy, R., Sato, M., and Lo, K.: Global surface temperature change, Rev. Geophys., 48, RG4004, doi:10.1029/2010RG000345, 2010.

$\mathrm{Hu}$, Y. and Fu, Q.: Observed poleward expansion of the Hadley circulation since 1979, Atmos. Chem. Phys., 7, 5229-5236, doi:10.5194/acp-7-5229-2007, 2007.

Hu, Y., Li, D., and Liu, J.: Abrupt seasonal variation of the ITCZ and the Hadley circulation, Geophys. Res. Lett., 34, L18814, doi:10.1029/2007GL030950, 2007.

Hudson, R., Frolov, A., Andrade, M., and Follette, M.: The total ozone field separated into meteorological regimes, Part I: Defining the regimes, J. Atmos. Sci., 60, 1669-1677, 2003.
Johanson, C. and Fu, Q.: Hadley cell widening: Model simulations versus observations, J. Climate, 22, 2713-2725, 2009.

Jones, P., New, M., Parker, D., Martin, S., and Rigor, I.: Surface air temperature and its variations over the last 150 years, Rev. Geophys., 37, 173-199, 1999.

Kistler, R., Kalnay, E., Collins, W., Saha, S., White, G., Woollen, J., Chelliah, M., Ebisuzaki, W., Kanamitsu, M., Kousky, V., van den Dool, H., Jenne, R., and Fiorino, M.: The NCEP-NCAR 50Year Reanalysis: Monthly Means CD-ROM and Documentation, B. Am. Meteorol. Soc., 82, 247-268, 2001.

Lu, J., Vecchi, G., and Reichler, T.: Expansion of the Hadley cell under global warming, Geophys. Res. Lett., 34, L06805, doi:10.1029/2006GL028443, 2007.

Mitas, C. and Clement, A.: Has the Hadley cell been strengthening in recent decades?, Geophys. Res. Lett., 32, L03809, doi:10.1029/2004GL021765, 2005.

Mitas, C. and Clement, A.: Recent behavior of the Hadley cell and tropical thermodynamics in climate models and reanalyses, Geophys. Res. Lett., 33, L03809, doi:10.1029/2005GL024406, 2006.

Oort, A. and Yienger, J.: Observed interannual variability in the Hadley circulation and its connection to ENSO, J. Climate, 9, 2751-2767, 1996.

Poore, R., Quinn, T., and Verardo, S.: Century-scale movement of the Atlantic Intertropical Convergence Zone linked to solar variability, Geophys. Res. Lett., 31, L12214, doi:10.1029/2004GL019940, 2004.

Santer, B., Wigley, T., Mears, C., Wentz, F., Klein, S., Seidel, D., Taylor, K., Thorne, P., Wehner, M., Gleckler, P., Boyle, J., Collins, W., Dixon, K., Doutriaux, C., Free, M., Fu, Q., Hansen, J., Jones, G., Ruedy, R., Karl, T., Lanzante, J., Meehl, G., Ramaswamy, V., Russell, G., and Schmidt, G.: Amplification of surface temperature trends and variability in the tropical atmosphere, Science, 309, 1551-1556, 2005.

Schneider, T., O'Gorman, P., and Levine, X.: Water vapor and the dynamics of climate changes, Rev. Geophys., 48, RG3001, doi:10.1029/2009RG000302, 2010.

Seidel, D. and Randel, W.: Recent widening of the tropical belt: Evidence from tropopause observations, J. Geophys. Res., 112, D20113, doi:10.1029/2007JD008861, 2007.

Sherwood, S.: Simultaneous detection of climate change and observing biases in a network with incomplete sampling, J. Climate, 20, 4047-4062, 2007.

Song, H. and Zhang, M.: Changes of the boreal winter hadley circulation in the NCEP-NCAR and ECMWF reanalyses: a comparative study, J. Climate, 20, 5191-5200, 2007.

Tanaka, H., Ishizaki, N., and Nohara, D.: Intercomparison of the intensities and trends of Hadley, Walker and monsoon circulations in the global warming projections, SOLA, 1, 77-80, 2005.

Vecchi, G. and Soden, B.: Global Warming and the Weakening of the Tropical Circulation, J. Climate, 20, 4316-4340, 2007.

Whitaker, J., Compo, G., Wei, X., and Hamill, T.: Reanalysis without radiosondes using ensemble data assimilation, Mon. Weather Rev., 132, 1190-1200, 2004.

Wielicki, B., Wong, T., Allan, R., Slingo, A., Kiehl, J., Soden, B., Gordon, C., Miller, A., Yang, S., Randall, D., Robertson, F., Susskind, J., and Jacobowitz, H.: Evidence for large decadal variability in the tropical mean radiative energy budget, Science, 295, 841-844, 2002. 